Annals of Pure and Applied Mathematics

Vol. 16, No. 2, 2018, 401-411

ISSN: 2279-087X (P), 2279-0888(online)

Published on 11 March 2018

www.researchmathsci.org

DOI: http://dx.doi.org/10.22457/apam.v16n2a17

Annals of

Pure and Applied

Mathematics

\title{
On Minimal Topological Totally Closed Graphs
}

\author{
D. Sheeba ${ }^{1}$ and N. Nagaveni ${ }^{2}$ \\ Department of Mathematics \\ Coimbatore Institute of Technology, Coimbatore-14, Tamil Nadu, India. \\ Email: ${ }^{1}$ sheebarinald@gmail.com and ${ }^{2}$ nagavenipalanisamy@yahoo.com \\ ${ }^{1}$ Corresponding author
}

Received 16 February 2018; accepted 5 March 2018

Abstract. In this paper, we introduced and studied some properties of new functions such as quasi mwg-continuous, totally mwg-continuous functions with $m_{w g}$ - closed graph and totally $m_{w g}$ - closed graph in minimal structures.

Keywords: $m_{w g^{-}}$closed graph, totally $m_{w g^{-}}$closed graph, $m_{w g^{-}}$compact, $m_{w g^{-}}$ connected

\section{AMS Mathematics Subject Classification (2010): 54C10}

\section{Introduction}

In 2000, Popa and Noiri [12] investigated the concept of minimal structure which is more general than a topological space. Moreover, he studied properties of M-continuous function's concept between spaces with minimal structures and obtained some characterizations and aspects of these functions.

On the other hand, they gave the definitions of $\mathrm{m}$ - closed graph [8] and strongly m-closed graph [8] together with their properties. In 2012, Min et al. [5] studied m-semi closed graph and strongly $\mathrm{m}$-semi closed graph. Many mathematicians have defined some types of open sets, continuities and closed graphs which are generalizations of m-open sets, $M$-continuity and $m$-closed graphs, in spaces with minimal structures. Since the advent of these notions, several research papers with interesting results in different respects came to existence $[3,4,6,7,13,14]$. Recently, Ghosh [2] studied separation axioms and graph functions in nano topological spaces. In 1995, Nour et al., investigated totally semi-continuous Functions [10]. In 2009, Caldas et al., studied the properties of totally b-continuous functions [1] in topological spaces.

In this paper, we introduced and investigated some properties of new functions such as quasi mwg-continuous, totally mwg-continuous functions with $m_{w g^{-}}$closed graph and totally $m_{w g^{-}}$closed graph. Also, we defined some new spaces called $m_{w g^{-}}$ Haussdroff space, totally $m_{w g}$-Compact, totally $m_{w g}$-Connected and etc., in order to characterize these spaces by using the notion of closed graphs.

Throughout the paper $\left(\mathrm{X}, m_{X}\right)$ and $\left(\mathrm{Y}, m_{Y}\right)$ are denoted by topological spaces with minimal structure (briefly. m-space). The interior and closure of a subset $\mathrm{A}$ of $\left(\mathrm{X}, m_{X}\right)$ are denoted by $m_{X}-\operatorname{Int}(\mathrm{A})$ and $m_{X}-\mathrm{Cl}(\mathrm{A})$ respectively. 


\section{Sheeba and N. Nagaveni}

\section{Preliminaries}

In this section, we list some definitions which are used in this sequel.

Definition 2.1. [8] Let $X$ be a non empty set and $P(X)$ the power set of $X$. A subfamily $m_{X}$ of $\mathrm{P}(\mathrm{X})$ is called a minimal structure (briefly m-structure) on $\mathrm{X}$ if $\Phi \in m_{X}$ and $\mathrm{X} \in$ $m_{X}$.

By $\left(\mathrm{X}, m_{X}\right)$, we denote a nonempty set $\mathrm{X}$ with an $\mathrm{m}$-structure $m_{X}$ on $\mathrm{X}$ and call it an m-space. Each member of $m_{X}$ is said to be $m_{X}$-open and the complement of an $m_{X}$ -open set is said to be $m_{X}$-closed.

Definition 2.2. [8] An m-structure $m_{X}$ on a nonempty set $X$ is said to have property $B$ if the union of any family of subsets belong to $m_{X}$ belongs to $m_{X}$.

Definition 2.3. [8] Let $X$ be a nonempty set and $m_{X}$ an m-structure on $X$. For subset A of $\mathrm{X}$, the $m_{X}$-closure of $\mathrm{A}$ and the $m_{X}$-interior of $\mathrm{A}$ are defined in as follows

i. $\quad m_{X}-\mathrm{Cl}(\mathrm{A})=\cap\left\{\mathrm{F}: \mathrm{A} \subset \mathrm{F}, \mathrm{X}-\mathrm{F} \in m_{X}\right\}$,

ii. $\quad m_{X}-\operatorname{Int}(\mathrm{A})=U\left\{\mathrm{U}: \mathrm{U} \subset \mathrm{A}, \mathrm{U} \in m_{X}\right\}$.

Definition 2.4. [11] A subset A of a m-space $\left(X, m_{X}\right)$ is said to be

i. $\quad$ minimal generalized closed (mg-closed) sets if $m_{X}-\mathrm{Cl}(\mathrm{A}) \subset \mathrm{U}$ whenever $\mathrm{A}$ $\subset \mathrm{U}$ and $\mathrm{U}$ is open in $m_{X}$.

ii. minimal weakly generalized closed (mwg-closed) sets if $m_{X}-\mathrm{Cl}\left(m_{X}\right.$ $\operatorname{Int}(\mathrm{A})) \subset \mathrm{U}$ whenever $\mathrm{A} \subset \mathrm{U}$ and $\mathrm{U}$ is open in $m_{X}$.

The complement of mg-closed set (resp. mwg-closed set) is said to be mg-open set (resp. mwg-open set). The family of all mg-open sets (resp. mwg-open set) is denoted by $m_{X^{-}}$ $\mathrm{GO}(\mathrm{X})$ (resp. $\left.m_{X}-\mathrm{WGO}(\mathrm{X})\right)$. We set $m_{X}-\mathrm{GO}(\mathrm{X}, \mathrm{x})=\left\{\mathrm{V} \in m_{X}-\mathrm{GO}(\mathrm{X}) / \mathrm{x} \in\right.$ $\mathrm{V}\}$ for $\mathrm{x} \in m_{X}$. We define similarly, $m_{X}-\mathrm{WGO}(\mathrm{X}, \mathrm{x})=\left\{\mathrm{V} \in m_{X}-\mathrm{WGO}(\mathrm{X}) / \mathrm{x}\right.$ $\in \mathrm{V}\}$ for $\mathrm{x} \in m_{X}$.

Definition 2.5. [8] A function $\mathrm{f}:\left(\mathrm{X}, m_{X}\right) \rightarrow\left(\mathrm{Y}, m_{Y}\right)$ is said to be M-closed graph (resp. strongly M-closed graph) if for each $(\mathrm{x}, \mathrm{y}) \in(\mathrm{X} \times \mathrm{Y})-\mathrm{G}(\mathrm{f})$, there exist $m_{X}$-open set $\mathrm{U}$ containing $\mathrm{x}$ and $m_{Y}$-open set $\mathrm{V}$ containing y such that $(\mathrm{U} \times \mathrm{V}) \cap \mathrm{G}(\mathrm{f})=\Phi\left(\left(\mathrm{U} \times m_{Y}\right.\right.$ $\mathrm{Cl}(\mathrm{V})) \cap \mathrm{G}(\mathrm{f})=\Phi)$.

Definition 2.6. [6] A m-space $\left(\mathrm{X}, m_{X}\right)$ is said to be

i. $\quad \mathrm{m}_{-} \mathrm{T}_{2}$ if for any distinct points $\mathrm{x}, \mathrm{y}$ there exists $\mathrm{U}, \mathrm{V} \in m_{X}$ such that $\mathrm{x} \in \mathrm{U}, \mathrm{y}$ $\in \mathrm{V}$ and $\mathrm{U} \cap \mathrm{V}=\Phi$.

ii. $\quad \mathrm{m}-\mathrm{Urysohn}$ if for any distinct points $\mathrm{x}, \mathrm{y}$ there exists $\mathrm{U}, \mathrm{V} \in m_{X}$ such that $\mathrm{x} \in$ $\mathrm{U}, \mathrm{y} \in \mathrm{V}$ and $m_{X}-\mathrm{Cl}(\mathrm{U}) \cap m_{X}-\mathrm{Cl}(\mathrm{V})=\Phi$.

iii. $\quad m$-Lindelöf [9] if every $m_{X}$-open cover of $X$ has a countable subcover.

Definition 2.7. A function $\mathrm{f}:\left(\mathrm{X}, m_{X}\right) \rightarrow\left(\mathrm{Y}, m_{Y}\right)$ is said to be

i. $\mathrm{m}$-continuous [6] if the inverse image of every $\mathrm{m}-\operatorname{closed}$ set in $\left(\mathrm{Y}, m_{Y}\right)$ is $\mathrm{m}$ - closed in $\left(\mathrm{X}, m_{X}\right)$. 
On Minimal Topological Totally Closed Graphs

ii. mwg-continuous [11] if $\mathrm{f}^{-1}(\mathrm{~V})$ is mwg-closed in $\left(\mathrm{X}, m_{X}\right)$ for every mwgclosed set $\mathrm{V}$ in $\left(\mathrm{Y}, m_{Y}\right)$.

Lemma 2.8. [8] Let $\left(X, m_{X}\right)$ be a space with minimal structure, let $A$ be a subset of $X$ and $\mathrm{x} \in \mathrm{X}$. Then $\mathrm{x} \in m_{X}-\mathrm{Cl}(\mathrm{A})$ if and only if $\mathrm{U} \cap \mathrm{A} \neq \Phi$, for every $\mathrm{U} \in m_{X}$ containing the point $\mathrm{X}$.

\section{Minimal weakly generalized closed graph $\left(m_{w g}\right.$-closed graph)}

In this section, we defined and studied some functions with minimal weakly generalized closed graph.

Definition 3.1. A function $\mathrm{f}:\left(\mathrm{X}, m_{X}\right) \rightarrow\left(\mathrm{Y}, m_{Y}\right)$ is said to be minimal weakly generalized closed graph (briefly. $m_{w g}$ - closed graph) if for each (x, y) $\in(X \times Y)-G(f)$, there exist $\mathrm{U} \in m_{w g}-\mathrm{WGO}(\mathrm{X}, \mathrm{x})$ and $\mathrm{V} \in m_{w g}-\mathrm{WGO}(\mathrm{Y}, \mathrm{y})$ such that $(\mathrm{U} \times \mathrm{V}) \cap \mathrm{G}(\mathrm{f})=$ $\Phi$.

Lemma 3.2. A function $\mathrm{f}:\left(\mathrm{X}, m_{X}\right) \rightarrow\left(\mathrm{Y}, m_{Y}\right)$ is said to be $m_{w g}$-closed graph if for each $(\mathrm{x}, \mathrm{y}) \in(\mathrm{X} \times \mathrm{Y})-\mathrm{G}(\mathrm{f})$, there exist $\mathrm{U} \in m_{X}-\mathrm{WGO}(\mathrm{X}, \mathrm{x})$ and $\mathrm{V} \in m_{Y}-\mathrm{WGO}(\mathrm{Y}, \mathrm{y})$ such that $\mathrm{f}(\mathrm{U}) \cap \mathrm{V}=\Phi$.

Proof is obvious from the Definition 3.1.

Theorem 3.3. Every function with $\mathrm{m}$-closed graph has a $m_{w g}$-closed graph. Proof follows from the Lemma 3.4 [11] that a m-closed set is mwg-closed set.

Theorem 3.4. Every function with a mg-closed graph has a $m_{w g}$-closed graph. Proof follows from the Theorem 3.2 [11] that a mg-closed set is mwg-closed set.

Remark 3.5. Every m-closed set is mg-closed set. But converse need not be true as seen from the following example.

Example 3.6. Let $X=\{a, b, c\}$ be endowed with the minimal structures $m_{X}=$ $\{X, \varnothing,\{a\},\{b\},\{c\}\}$. Here $\{a\},\{b\}$ and $\{c\}$ are mg-closed sets. But which are not m-closed set.

Theorem 3.7. Every function with $\mathrm{m}$-closed graph has a mg-closed graph.

Proof follows from the Remark 3.5 that a m-closed set is mg-closed set.

From above discussion we have the following implications:

$$
\mathrm{m} \text {-closed graph } \longrightarrow
$$

$$
m_{w g} \text {-closed graph }
$$

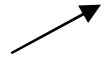

Figure 1:

Remark 3.8. The converse need not be true for the above implications as shown by the following examples stated below. 


\section{Sheeba and N. Nagaveni}

Example 3.9. Let $X=\{a, b, c\}$ and $Y=\{a, b, c, d\}$ be endowed with the minimal structures $m_{X}=\{\mathrm{X}, \emptyset,\{\mathrm{a}\},\{\mathrm{b}\},\{\mathrm{c}\}\}$ and $m_{Y}=\{\mathrm{Y}, \emptyset,\{\mathrm{a}, \mathrm{b}\},\{\mathrm{a}, \mathrm{d}\},\{\mathrm{a}, \mathrm{b}, \mathrm{d}\}\}$ respectively. Let $\mathrm{f}:\left(\mathrm{X}, m_{X}\right) \rightarrow\left(\mathrm{Y}, m_{Y}\right)$ be the mapping defined by $\mathrm{f}(\mathrm{a})=\mathrm{a}, \mathrm{f}(\mathrm{b})=\mathrm{b}$. Then $\mathrm{f}$ has $m_{w g}$-closed graph. But it is not m-closed graph.

Example 3.10. Let $X=\{a, b, c, d\}=Y$ be endowed with the minimal structures $m_{X}=$ $\{\mathrm{X}, \emptyset,\{\mathrm{a}\},\{\mathrm{a}, \mathrm{c}\}\}$ and $m_{Y}=\{\mathrm{Y}, \emptyset,\{\mathrm{a}, \mathrm{b}\},\{\mathrm{a}, \mathrm{d}\},\{\mathrm{a}, \mathrm{b}, \mathrm{d}\}\}$ respectively. Let $\mathrm{f}:\left(\mathrm{X}, m_{X}\right) \rightarrow$ $\left(\mathrm{Y}, m_{Y}\right)$ be the mapping defined by $\mathrm{f}(\mathrm{a})=\mathrm{a}, \mathrm{f}(\mathrm{b})=\mathrm{b}$. Then $\mathrm{f}$ has $m_{w g}$-closed graph. But it is not mg-closed graph.

Example 3.11. Let $X=\{a, b, c\}$ and $Y=\{a, b, c, d\}$ be endowed with the minimal structures $m_{X}=\{\mathrm{X}, \emptyset,\{\mathrm{a}\},\{\mathrm{b}\},\{\mathrm{c}\}\}$ and $m_{Y}=\{\mathrm{Y}, \emptyset,\{\mathrm{a}, \mathrm{b}\},\{\mathrm{c}, \mathrm{d}\}\}$ respectively. Let $\mathrm{f}:\left(\mathrm{X}, m_{X}\right) \rightarrow\left(\mathrm{Y}, m_{Y}\right)$ be the mapping defined by $\mathrm{f}(\mathrm{a})=\mathrm{a}, \mathrm{f}(\mathrm{b})=\mathrm{b}$. Then $\mathrm{f}$ has $\mathrm{mg}$ closed graph. But it is not m-closed graph.

Definition 3.12. A m-space $\left(X, m_{X}\right)$ is called

i. $\quad m_{w g}-\mathrm{T}_{1}$ space if for every pair of distinct points $\mathrm{x}, \mathrm{y}$ in $\mathrm{X}$ there exists a mwgopen set $\mathrm{U} \in \mathrm{X}$ containing $\mathrm{x}$ but not $\mathrm{y}$ and a mwg-open set $\mathrm{V} \in \mathrm{X}$ containing $\mathrm{y}$ but not $\mathrm{x}$.

ii. $\quad m_{w g}$-Haussdroff space (i.e. $m_{w g}-\mathrm{T}_{2}$ space) if for every pair of distinct points $\mathrm{x}, \mathrm{y}$ in $\mathrm{X}$ there exists disjoint mwg-open sets $\mathrm{U} \in \mathrm{X}$ and $\mathrm{V} \in \mathrm{X}$ containing $\mathrm{x}$ and $\mathrm{y}$ respectively.

Theorem 3.13. If $\mathrm{f}:\left(\mathrm{X}, m_{X}\right) \rightarrow\left(\mathrm{Y}, m_{Y}\right)$ is an injective function with the $m_{w g}$-closed graph $\mathrm{G}(\mathrm{f})$, then $\mathrm{X}$ is $m_{w g}-\mathrm{T}_{1}$.

Proof: Let $x$ and $y$ be two distinct points of $X$. Since $f$ is injection, $\mathrm{f}(\mathrm{x}) \neq \mathrm{f}(\mathrm{y})$ in $Y$. $(\mathrm{x}, \mathrm{f}(\mathrm{y})) \in(\mathrm{X} \times \mathrm{Y})-\mathrm{G}(\mathrm{f})$. But $\mathrm{G}(\mathrm{f})$ is $m_{w g}$-closed graph. So, by the Lemma 3.2, there exist mwg-open sets $\mathrm{U}$ and $\mathrm{V}$ containing $\mathrm{x}$ and $\mathrm{f}(\mathrm{y})$ respectively, such that $\mathrm{f}(\mathrm{U}) \cap \mathrm{V}=\varnothing$. Hence $\mathrm{y} \notin \mathrm{U}$. Similarly, there exist mwg-open sets $\mathrm{M}$ and $\mathrm{N}$ containing y and $\mathrm{f}(\mathrm{x})$ such that $\mathrm{f}(\mathrm{M}) \cap \mathrm{N}=\emptyset$. Hence $\mathrm{x} \notin \mathrm{M}$. It follows that $\mathrm{X}$ is $m_{w g}-\mathrm{T}_{1}$ space.

Theorem 3.13. If $\mathrm{f}:\left(\mathrm{X}, m_{X}\right) \rightarrow\left(\mathrm{Y}, m_{Y}\right)$ is a surjective function with the $m_{w g}$-closed graph G(f), then $\mathrm{Y}$ is $m_{w g}-\mathrm{T}_{1}$.

Proof: Let $y$ and $z$ be two distinct points of $Y$. Since $f$ is surjective, there exist a point $x$ in $X$ such that $f(x)=z$. Therefore $(x, y) \notin G(f)$, by the Lemma 3.2 there exist mwg-open sets $U$ and $V$ containing $x$ and $y$ respectively such that $f(U) \cap V=\varnothing$. It follows that $z \notin$ $\mathrm{V}$.

Similarly, there exist $w \in X$ such that $f(w)=y$. Hence $(w, z) \notin G(f)$. Similarly, there exist mwg-open sets $M$ and $N$ containing $w$ and $z$ respectively such that $f(M) \cap N=\emptyset$. Thus $\mathrm{y} \notin \mathrm{N}$, hence the space $\mathrm{Y}$ is $m_{w g}-\mathrm{T}_{1}$. 


\section{On Minimal Topological Totally Closed Graphs}

Theorem 3.14. If a function $\mathrm{f}:\left(\mathrm{X}, m_{X}\right) \rightarrow\left(\mathrm{Y}, m_{Y}\right)$ is mwg-continuous and $\mathrm{Y}$ is $m_{w g}-\mathrm{T}_{2}$ space, then $\mathrm{G}(\mathrm{f})$ is $m_{w g}$-closed.

Proof: Let $(\mathrm{x}, \mathrm{y}) \notin \mathrm{G}(\mathrm{f})$ or $(\mathrm{x}, \mathrm{y}) \in \mathrm{X} \times \mathrm{Y}-\mathrm{G}(\mathrm{f})$, then $\mathrm{y} \neq \mathrm{f}(\mathrm{x})$ and $\mathrm{Y}$ is $m_{w g}-\mathrm{T}_{2}$ space. There exist two mwg-open sets $U$ and $V$ such that $f(x) \in U, y \in V$ in $Y$ and $U \cap V=\varnothing$. Since $\mathrm{f}$ is mwg-continuous, there exist a mwg-open neighbourhood $\mathrm{W}$ of $\mathrm{x}$ such that $\mathrm{f}(\mathrm{W}) \subset \mathrm{U}$. Hence $\mathrm{f}(\mathrm{W}) \cap \mathrm{V}=\varnothing$ and this implies that $(\mathrm{W} \times \mathrm{V}) \cap \mathrm{G}(\mathrm{f})=\emptyset$. Hence $\mathrm{f}$ has a $m_{w g}$-closed graph.

Definition 3.15. A function $\mathrm{f}:\left(\mathrm{X}, m_{X}\right) \rightarrow\left(\mathrm{Y}, m_{Y}\right)$ is called quasi-mwg-continuous if for each $\mathrm{x} \in \mathrm{X}$ and each $\mathrm{V} \in m_{X}$ containing $\mathrm{f}(\mathrm{x})$, there exists a $\mathrm{U} \in m_{X}-\mathrm{GO}(\mathrm{X}, \mathrm{x})$ such that $\mathrm{f}(\mathrm{U}) \subset m_{X}-\mathrm{Cl}(\mathrm{V})$.

Remark 3.16. Every mwg-continuous function is quasi-mwg-continuous. But converse need not be true as seen from following example.

Example 3.17. Let $X=\{a, b, c\}$ and $Y=\{a, b, c, d\}$ be endowed with the minimal structures $m_{X}=\{\mathrm{X}, \emptyset,\{\mathrm{a}, \mathrm{b}\},\{\mathrm{b}, \mathrm{c}\}\}$ and $m_{Y}=\{\mathrm{Y}, \emptyset,\{\mathrm{a}, \mathrm{b}\},\{\mathrm{a}, \mathrm{d}\},\{\mathrm{a}, \mathrm{b}, \mathrm{d}\}\}$ respectively. Let $\mathrm{f}:\left(\mathrm{X}, m_{X}\right) \rightarrow\left(\mathrm{Y}, m_{Y}\right)$ be the mapping defined by $\mathrm{f}(\mathrm{a})=\mathrm{a}, \mathrm{f}(\mathrm{b})=\mathrm{b}$. Then $\mathrm{f}$ has quasi-mwg-continuous. But it is not mwg-continuous.

Theorem 3.18. If $\mathrm{f}:\left(\mathrm{X}, m_{\mathrm{X}}\right) \rightarrow\left(\mathrm{Y}, m_{\mathrm{Y}}\right)$ is quasi-mwg-continuous and $\mathrm{Y}$ is $\mathrm{m}-\mathrm{T}_{2}$, then $\mathrm{f}$ has the following property:

(P) For each $(\mathrm{x}, \mathrm{y}) \notin \mathrm{G}(\mathrm{f})$ there exist $\mathrm{U} \in m_{X}-\mathrm{WGO}(\mathrm{X}, \mathrm{x})$ and $\mathrm{V} \in m_{Y}$ containing $\mathrm{y}$, such that $\mathrm{f}(\mathrm{U}) \cap m_{Y}-\operatorname{Int}\left(m_{Y}-\mathrm{Cl}(\mathrm{V})\right)=\Phi$.

Proof: Suppose (x, y) $\notin \mathrm{G}(\mathrm{f})$. Then $\mathrm{y} \neq \mathrm{f}(\mathrm{x})$. Since $\mathrm{Y}$ is $\mathrm{m}-\mathrm{T}_{2}$, there exist $\mathrm{V}, \mathrm{W} \in m_{Y}$ such that $\mathrm{y} \in \mathrm{V}, \mathrm{f}(\mathrm{x}) \in \mathrm{W}$ and $\mathrm{V} \cap \mathrm{W}=\Phi$. It is easy to verify that $m_{Y^{-}} \operatorname{Int}\left(m_{Y^{-}} \mathrm{Cl}(\mathrm{V})\right) \cap m_{Y^{-}}$ $\mathrm{Cl}(\mathrm{W})=\Phi$. The quasi-mwg-continuous of $\mathrm{f}$ gives a $\mathrm{U} \in m_{X}-\mathrm{WGO}(\mathrm{X}, \mathrm{x})$ such that $\mathrm{f}(\mathrm{U})$ $\subset m_{X}-\mathrm{Cl}(\mathrm{V})$ and hence $\mathrm{f}(\mathrm{U}) \cap m_{Y}-\operatorname{Int}\left(m_{Y}-\mathrm{Cl}(\mathrm{V})\right)=\Phi$.

Theorem 3.19. if $\mathrm{f}:\left(\mathrm{X}, m_{X}\right) \rightarrow\left(\mathrm{Y}, m_{Y}\right)$ is quasi-mwg-continuous and $\mathrm{Y}$ is $\mathrm{m}-\mathrm{T}_{2}$, then G(f) $m_{w g}$-closed.

Proof: If $(\mathrm{x}, \mathrm{y}) \in \mathrm{X} \times \mathrm{Y}-\mathrm{G}(\mathrm{f})$, then there exist a $\mathrm{U} \in m_{X}$-WGO(X, $\left.\mathrm{x}\right)$ and $\mathrm{V} \in m_{Y}$ containing y, such that $\mathrm{f}(\mathrm{U}) \cap m_{Y}-\operatorname{Int}\left(m_{Y}-\mathrm{Cl}(\mathrm{V})\right)=\Phi$. Hence $\mathrm{f}(\mathrm{U}) \cap \mathrm{V}=\Phi$ so that $(\mathrm{U} \times$ $\mathrm{V}) \cap \mathrm{G}(\mathrm{f})=\Phi$. Thus $(\mathrm{x}, \mathrm{y}) \in(\mathrm{U} \times \mathrm{V}) \subset \mathrm{X} \times \mathrm{Y}-\mathrm{G}(\mathrm{f})$ where $\mathrm{U} \times \mathrm{V}$ is mwg-open set in $\mathrm{X} \times \mathrm{Y}$. Hence $\mathrm{G}(\mathrm{f})$ is $m_{w g}$-closed.

Definition 3.20. A subset $K$ of a nonempty set $X$ with a minimal structure $m_{X}$ is said to be $m_{w g}$-compact relative to $\left(\mathrm{X}, m_{X}\right)$ if any cover of $\mathrm{K}$ by every mwg-open sets has a finite subcover.

Theorem 3.21. Let $\mathrm{f}:\left(\mathrm{X}, m_{X}\right) \rightarrow\left(\mathrm{Y}, m_{Y}\right)$ be a function. Assume that $m_{X^{-}}$is a base for a topology. If the graph $\mathrm{G}(\mathrm{f})$ is $m_{w g}$-closed, then $m_{X}-\mathrm{Cl}\left(\mathrm{f}^{-1}(\mathrm{~K})\right)=\mathrm{f}^{-1}(\mathrm{~K})$ whenever the set $\mathrm{K} \subseteq \mathrm{Y}$ is $m_{w g}$-Compact relative to $\left(\mathrm{Y}, m_{Y}\right)$.

Proof: Let $\mathrm{K} \subseteq \mathrm{Y}$ be $m_{w g}$-Compact relative to $\left(\mathrm{Y}, m_{Y}\right)$ and $\mathrm{x} \in \mathrm{X}-\mathrm{f}^{-1}(\mathrm{~K})$, for each y $\in$ $\mathrm{K}$ we have $(\mathrm{x}, \mathrm{y}) \in \mathrm{X} \times \mathrm{Y}-\mathrm{G}(\mathrm{f})$, hence by the lemma 3.2 there exist an mwg - open sets 


\section{Sheeba and N. Nagaveni}

$\mathrm{U}_{\mathrm{y}}$ containing $\mathrm{x}$ and mwg-open set $\mathrm{V}_{\mathrm{y}}$ containing y such that $\mathrm{f}(\mathrm{U}) \cap \mathrm{V}=\Phi$. The family $\left\{\mathrm{V}_{\mathrm{y}}: \mathrm{y} \in \mathrm{K}\right\}$ is a cover of $\mathrm{K}$ by $\mathrm{mwg}$ - open sets. Since $\mathrm{K} \subseteq \mathrm{Y}$ is $m_{w g}$-Compact relative to $\left(\mathrm{Y}, m_{Y}\right)$, there exists a finite subset of $\mathrm{K}$, say $\left\{\mathrm{y}_{1}, \mathrm{y}_{2}, \ldots, \mathrm{y}_{\mathrm{n}}\right\}$, such that $\mathrm{K} \subseteq \mathrm{U}\left\{\mathrm{V}_{y_{k}}\right.$ : $k=1,2, \ldots n\}$. Then $\mathrm{f}^{-1}(\mathrm{~K}) \subseteq \mathrm{U}\left\{f^{-1}\left(V_{y_{k}}: k=1,2, \ldots, n\right\}\right.$. Hence $\mathrm{f}^{-1}(\mathrm{~K}) \subseteq \mathrm{U}\{\mathrm{X} \backslash$ Uyk : $\mathrm{k}=1,2, \ldots, \mathrm{n}\}=\mathrm{X} \backslash \cap\left\{\mathrm{U}_{\mathrm{yk}}: \mathrm{k}=1,2, \ldots, \mathrm{n}\right\}$. Assume that $m_{X}$ - is a base for a topology, there exist $\mathrm{U} \in m_{X}$ containing $\mathrm{x}$ such that $\mathrm{U} \subseteq \cap\left\{\mathrm{U}_{\mathrm{yk}}: \mathrm{k}=1,2, \ldots, \mathrm{n}\right\}$. Then $\mathrm{U} \cap \mathrm{f}^{-1}(\mathrm{~K})$ $=\Phi$, which shows, according to Lemma 2.8 , that $\mathrm{x} \in \mathrm{X} \backslash m_{X}-\mathrm{Cl}\left(\mathrm{f}^{-1}(\mathrm{~K})\right)$. We proved that $\mathrm{X} \backslash \mathrm{f}^{-1}(\mathrm{~K}) \subseteq \mathrm{X} \backslash m_{X}-\mathrm{Cl}\left(\mathrm{f}^{-1}(\mathrm{~K})\right)$, whence $\mathrm{Cl}\left(\mathrm{f}^{-1}(\mathrm{~K})\right)=\mathrm{f}^{-1}(\mathrm{~K})$.

\section{Totally $m_{w g}$-closed graph}

In this section, we defined and studied some functions with totally $m_{w g}$-closed graph.

Definition 4.1. A subset $A$ of space $\left(X, m_{X}\right)$ is called

i. $\quad \mathrm{m}$-clopen if $\mathrm{A}$ is $\mathrm{m}$-closed and $\mathrm{m}$-open sets in $\mathrm{X}$.

ii. mwg-clopen if $\mathrm{A}$ is mwg-closed and mwg-open sets in $\mathrm{X}$.

The family of all m-clopen sets (resp. mwg-clopen set) is denoted by $m_{X}-\mathrm{CO}(\mathrm{X})$ (resp. $m_{X}-\mathrm{WGCO}(\mathrm{X})$ ). We set $m_{X}-\mathrm{CO}(\mathrm{X}, \mathrm{x})=\left\{\mathrm{V} \in m_{X}-\mathrm{CO}(\mathrm{X}) / \mathrm{x} \in \mathrm{V}\right\}$ for $\mathrm{x} \in m_{X}$. we define similarly, $m_{X}-\mathrm{WGCO}(\mathrm{X}, \mathrm{x})=\left\{\mathrm{V} \in m_{X}-\mathrm{WGCO}(\mathrm{X}) / \mathrm{x} \in \mathrm{V}\right\}$ for $\mathrm{x} \in m_{X}$.

Definition 4.2. A graph $\mathrm{G}(\mathrm{f})$ of a function $\mathrm{f}:\left(\mathrm{X}, m_{X}\right) \rightarrow\left(\mathrm{Y}, m_{Y}\right)$ is said to be totally $m_{w g}$-closed if for each $(\mathrm{x}, \mathrm{y}) \in(\mathrm{X} \times \mathrm{Y})-\mathrm{G}(\mathrm{f})$, there exists $\mathrm{U} \in m_{X}-\mathrm{WGCO}(\mathrm{X}, \mathrm{x})$ and $\mathrm{V} \in m_{X}-\mathrm{O}(\mathrm{Y}, \mathrm{y})$ such that $(\mathrm{U} \times \mathrm{V}) \cap \mathrm{G}(\mathrm{f})=\Phi$.

Lemma 4.3. A graph $\mathrm{G}(\mathrm{f})$ of a function $\mathrm{f}:\left(\mathrm{X}, m_{X}\right) \rightarrow\left(\mathrm{Y}, m_{Y}\right)$ is totally $m_{w g}$-closed in $(\mathrm{X} \times \mathrm{Y})$ if and only if for each $(\mathrm{x}, \mathrm{y}) \in(\mathrm{X} \times \mathrm{Y})-\mathrm{G}(\mathrm{f})$, there exists $\mathrm{U} \in m_{X}-\mathrm{WGCO}(\mathrm{X}$, $\mathrm{X})$ and $\mathrm{V} \in m_{X}-\mathrm{O}(\mathrm{Y}, \mathrm{y})$ such that $(\mathrm{U} \times \mathrm{V}) \cap \mathrm{G}(\mathrm{f})=\Phi$.

Proof: It is an immediate consequence of Definition 4.2.

Definition 4.4. A $m$-space $\left(X, m_{X}\right)$ is called

i. $\quad m_{w g}$ - clopen $\mathrm{T}_{1}$ (briefly. Mwgco- $\mathrm{T}_{1}$ ) space if for every pair of distinct points $\mathrm{x}, \mathrm{y}$ in $\mathrm{X}$ there exists a mwg-clopen set $\mathrm{U} \subset \mathrm{X}$ containing $\mathrm{x}$ but not $\mathrm{y}$ and $\mathrm{a}$ mwg-clopen set $\mathrm{V} \subset \mathrm{X}$ containing $\mathrm{y}$ but not $\mathrm{X}$.

ii. $\quad m_{w g}$-ultra hausdroff (briefly. Mwgco-T $\mathrm{T}_{2}$ ) space if for every pair of distinct points $\mathrm{x}, \mathrm{y}$ in $\mathrm{X}$ there exists disjoint mwg-clopen sets $\mathrm{U} \subset \mathrm{X}$ and $\mathrm{V} \subset \mathrm{X}$ containing $\mathrm{x}$ and $\mathrm{y}$ respectively.

Theorem 4.5. Let $\mathrm{f}:\left(\mathrm{X}, m_{X}\right) \rightarrow\left(\mathrm{Y}, m_{Y}\right)$ has totally $m_{w g}$-closed graph $\mathrm{G}(\mathrm{f})$. If $\mathrm{f}$ is injective, then $\mathrm{X}$ is $m_{w g}$ - clopen $\mathrm{T}_{1}$.

Proof: Let $x$ and $y$ be any two distinct points of $X$. Then, we have $(x, f(y)) \in(X \times Y)$ $G(f)$, By Lemma, there exists a mwg-clopen set $U$ of $X$ and m-open set $V$ of $Y$ such that $(\mathrm{x}, \mathrm{f}(\mathrm{y})) \in \mathrm{U} \times \mathrm{V}$ and $\mathrm{f}(\mathrm{U}) \cap \mathrm{V}=\Phi$. Hence $\mathrm{U} \cap \mathrm{f}^{-1}(\mathrm{~V})=\Phi$ and $\mathrm{y} \notin \mathrm{U}$. This implies that $\mathrm{X}$ is $m_{w g}$ - clopen $\mathrm{T}_{1}$.

Definition 4.6. A function $\mathrm{f}:\left(\mathrm{X}, m_{X}\right) \rightarrow\left(\mathrm{Y}, m_{Y}\right)$ is called 
On Minimal Topological Totally Closed Graphs

i. totally $\mathrm{m}$ - continuous at a point $\mathrm{x} \in \mathrm{X}$ if $\mathrm{f}^{-1}(\mathrm{~V})$ is $\mathrm{m}$-clopen set in $\left(\mathrm{X}, m_{X}\right)$ for each m-open set $\mathrm{V}$ of $\left(\mathrm{Y}, m_{Y}\right)$.

ii. totally $m_{w g^{-}}$continuous at a point $\mathrm{x} \in \mathrm{X}$ if $\mathrm{f}^{-1}(\mathrm{~V})$ is mwg-clopen set in $\left(\mathrm{X}, m_{X}\right)$ for each $\mathrm{m}$-open set $\mathrm{V}$ of $\left(\mathrm{Y}, m_{Y}\right)$.

\section{Remark 4.7.}

i. $\quad$ Every totally $m_{w g}$ - continuous is mwg- continuous functions. But converse need not be true from the following Example 4.8.

ii. Every totally $\mathrm{m}$ - continuous is totally $m_{w g^{-}}$continuous functions. But converse need not be true from the following Example 4.9.

Example 4.8. Let $\mathrm{X}=\{\mathrm{a}, \mathrm{b}, \mathrm{c}\}$ and $\mathrm{Y}=\{\mathrm{p}, \mathrm{q}, \mathrm{r}\}$ be the two topological spaces with $m_{X}$ $=\{\mathrm{X}, \Phi,\{\mathrm{a}\},\{\mathrm{b}\},\{\mathrm{a}, \mathrm{b}\}\}$ and $m_{Y}=\{\mathrm{Y}, \Phi,\{\mathrm{p}\}\}$. If $\mathrm{f}:\left(\mathrm{X}, m_{X}\right) \rightarrow\left(\mathrm{Y}, m_{Y}\right)$ is totally $m_{w g}$ - continuous function defined by $\mathrm{f}(\mathrm{a})=\{\mathrm{p}\}, \mathrm{f}(\mathrm{b})=\{\mathrm{q}\}$ and $\mathrm{f}(\mathrm{c})=\{\mathrm{r}\}$, then $\mathrm{f}$ is not mwg-continuous functions.

Example 4.9. Let $X=\{a, b, c\}$ and $Y=\{p, q, r\}$ be the two topological spaces with $m_{X}$ $=\{\mathrm{X}, \Phi,\{\mathrm{a}\},\{\mathrm{b}\},\{\mathrm{a}, \mathrm{b}\}\}$ and $m_{Y}=\{\mathrm{Y}, \Phi,\{\mathrm{q}\},\{\mathrm{p}, \mathrm{q}\}\}$. If $\mathrm{f}:\left(\mathrm{X}, m_{X}\right) \rightarrow\left(\mathrm{Y}, m_{Y}\right)$ is totally $m_{w g}$ - continuous function defined by $\mathrm{f}(\mathrm{a})=\{\mathrm{p}\}, \mathrm{f}(\mathrm{b})=\{\mathrm{q}\}$ and $\mathrm{f}(\mathrm{c})=\{\mathrm{r}\}$, then $\mathrm{f}$ is not totally m- continuous functions.

Theorem 4.10. If $\mathrm{f}:\left(\mathrm{X}, m_{X}\right) \rightarrow\left(\mathrm{Y}, m_{Y}\right)$ is totally $m_{w g^{-}}$continuous injection and $\mathrm{Y}$ is $m_{w g}-\mathrm{T}_{2}$, then $\mathrm{X}$ is $m_{w g}$-ultra hausdroff.

Proof: Let $\mathrm{x}_{1}, \mathrm{x}_{2} \in \mathrm{X}$ and $\mathrm{x}_{1} \neq \mathrm{x}_{2}$. Then, since $\mathrm{f}$ is injective, $\mathrm{f}\left(\mathrm{x}_{1}\right) \neq \mathrm{f}\left(\mathrm{x}_{2}\right)$ in $\left(\mathrm{Y}, m_{Y}\right)$. Since $\mathrm{Y}$ is $m_{w g}-\mathrm{T}_{2}$, there exist disjoint mwg-open sets $\mathrm{U} \subset \mathrm{Y}$ and $\mathrm{V} \subset \mathrm{Y}$ containing $\mathrm{f}\left(\mathrm{x}_{1}\right)$ and $\mathrm{f}\left(\mathrm{x}_{2}\right)$ respectively, and $\mathrm{U} \cap \mathrm{V}=\Phi$. This implies $\mathrm{x}_{1} \in \mathrm{f}^{-1}(\mathrm{U})$ and $\mathrm{x}_{2} \in \mathrm{f}^{-1}(\mathrm{~V})$. Since $\mathrm{f}$ is totally $m_{w g^{-}}$continuous, $\mathrm{f}^{-1}(\mathrm{U})$ and $\mathrm{f}^{-1}(\mathrm{~V})$ are mwg-clopen sets in $\mathrm{X}$. Also $\mathrm{f}^{-1}(\mathrm{U}) \cap \mathrm{f}^{-}$ ${ }^{1}(\mathrm{~V})=\mathrm{f}^{-1}(\mathrm{U} \cap \mathrm{V})=\Phi$. Thus every two distinct points of $\mathrm{X}$ can be separated by disjoint mwg-clopen sets. Therefore $\mathrm{X}$ is $m_{w g}$-ultra hausdroff.

Theorem 4.11. If $\mathrm{f}:\left(\mathrm{X}, m_{X}\right) \rightarrow\left(\mathrm{Y}, m_{Y}\right)$ is totally $m_{w g^{-}}$continuous and $\mathrm{Y}$ is $\mathrm{m}-\mathrm{T}_{2}$ then $\mathrm{G}(\mathrm{f})$ is totally $m_{w g}$-closed graph in product space $\mathrm{X} \times \mathrm{Y}$.

Proof: Let $(x, y) \in X \times Y$. Then $y \neq f(x)$ and there exists m-open sets $V_{1}$ and $V_{2}$ such that $\mathrm{f}(\mathrm{x}) \in \mathrm{V}_{1}, \mathrm{y} \in \mathrm{V}_{2}$ and $\mathrm{V}_{1} \cap \mathrm{V}_{2}=\Phi$. From the hypothesis there exists $\mathrm{U} \in m_{X}-\mathrm{WGCO}(\mathrm{X}$, $\mathrm{x}$ ) such that $\mathrm{f}(\mathrm{U}) \subset \mathrm{V}_{1}$. Therefore, we obtain $\mathrm{f}(\mathrm{U}) \cap \mathrm{V}_{2}=\Phi$.

Definition 4.12. A m-space $\left(X, m_{X}\right)$ is called

i. $\quad$ mwg-normal (resp. $m_{w g}$-ultra normal) if for each pair of non empty disjoint m-closed sets can be separated by disjoint mwg-open (resp. mwg-clopen) sets.

ii. mwg-regular (resp. $m_{w g}$-ultra regular) if for each mwg-closed set $\mathrm{F}$ of $\mathrm{X}$ and each $\mathrm{x} \notin \mathrm{F}$, there exist disjoint mwg-open (resp. mwg-clopen) sets $\mathrm{U}$ and $\mathrm{V}$ such that $\mathrm{F} \subset \mathrm{U}$ and $\mathrm{x} \in \mathrm{V}$. 


\section{Sheeba and N. Nagaveni}

Theorem 4.13. if $\mathrm{f}:\left(\mathrm{X}, m_{X}\right) \rightarrow\left(\mathrm{Y}, m_{Y}\right)$ is totally $m_{w g}$ - continuous, m-closed injective and $\mathrm{Y}$ is mwg-normal, then $\mathrm{X}$ is $m_{w g}$-ultra normal.

Proof: Let $U_{1}$ and $U_{2}$ be disjoint $m$-closed subsets of $X$. Since $f$ is $m$-closed and injective, $f\left(U_{1}\right)$ and $f\left(U_{2}\right)$ are disjoint m-closed subsets of $Y$. Since $Y$ is mwg-normal, $f\left(U_{1}\right)$ and $\mathrm{f}\left(\mathrm{U}_{2}\right)$ are separated by disjoint mwg-open sets $\mathrm{V}_{1}$ and $\mathrm{V}_{2}$ respectively. Therefore we obtain, $\mathrm{U}_{1} \subset \mathrm{f}^{-1}\left(\mathrm{~V}_{1}\right)$ and $\mathrm{U}_{2} \subset \mathrm{f}^{-1}\left(\mathrm{~V}_{2}\right)$. Since $\mathrm{f}$ is totally $m_{w g^{-}}$continuous, $\mathrm{f}^{-1}\left(\mathrm{~V}_{1}\right)$ and $\mathrm{f}^{-}$ ${ }^{1}\left(V_{2}\right)$ are mwg-clopen sets in $X$. Also, $\mathrm{f}^{-1}\left(\mathrm{~V}_{1}\right) \cap \mathrm{f}^{-1}\left(\mathrm{~V}_{2}\right)=\mathrm{f}^{-1}\left(\mathrm{~V}_{1} \cap \mathrm{V}_{2}\right)=\Phi$. Thus each non-empty disjoint $\mathrm{m}$-closed in $\mathrm{X}$ can be separated by disjoint mwg-clopen sets in $\mathrm{X}$. Therefore $\mathrm{X}$ is $m_{w g}$-ultra normal.

Definition 4.14. A function $\mathrm{f}:\left(\mathrm{X}, m_{X}\right) \rightarrow\left(\mathrm{Y}, m_{Y}\right)$ is called mwg-closed if $\mathrm{f}(\mathrm{U})$ is mwgclosed in $\mathrm{Y}$ for each $\mathrm{m}$-closed set $\mathrm{U}$ in $\mathrm{X}$.

Theorem 4.15. Let $\mathrm{f}:\left(\mathrm{X}, m_{X}\right) \rightarrow\left(\mathrm{Y}, m_{Y}\right)$ is totally $m_{w g}$ - continuous, mwg-closed injective. If $\mathrm{Y}$ is mwg-regular, then $\mathrm{X}$ is $m_{w g}$-ultra regular.

Proof: Let $U$ be a mwg-closed set not containing x. Since $f$ is mwg-closed, we have $f(U)$ is a mwg-closed set in $Y$ not containing $\mathrm{f}(\mathrm{x})$. Since $\mathrm{Y}$ is mwg-regular, there exist disjoint mwg-open sets $\mathrm{V}_{1}$ and $\mathrm{V}_{2}$ such that $\mathrm{f}(\mathrm{x}) \in \mathrm{V}_{1}$ and $\mathrm{f}(\mathrm{U}) \in \mathrm{V}_{2}$, which implies $\mathrm{x} \in \mathrm{f}^{-1}\left(\mathrm{~V}_{1}\right)$ and $\mathrm{U} \subset \mathrm{f}^{-1}\left(\mathrm{~V}_{2}\right)$, where $\mathrm{f}^{-1}\left(\mathrm{~V}_{1}\right)$ and $\mathrm{f}^{-1}\left(\mathrm{~V}_{2}\right)$ are mwg-clopen sets, because $\mathrm{f}$ is totally $m_{w g^{-}}$-continuous function. Moreover, since $\mathrm{f}$ is injective, $\mathrm{f}^{-1}\left(\mathrm{~V}_{1}\right) \cap \mathrm{f}^{-1}\left(\mathrm{~V}_{2}\right)=\mathrm{f}^{-1}\left(\mathrm{~V}_{1} \cap \mathrm{V}_{2}\right)$ $=\mathrm{f}^{-1}(\Phi)=\Phi$. Thus for each pair of point and a mwg-closed set not containing the point, they can be separated by disjoint mwg-clopen sets. Therefore $\mathrm{X}$ is is $m_{w g}$-ultra regular.

Definition 4.16. A function $\mathrm{f}:\left(\mathrm{X}, m_{X}\right) \rightarrow\left(\mathrm{Y}, m_{Y}\right)$ is said to be totally $m_{w g^{-}}$open if the image of every mwg-clopen subset of $\mathrm{X}$ is mwg-clopen.

Theorem 4.17. Let $\mathrm{f}:\left(\mathrm{X}, m_{X}\right) \rightarrow\left(\mathrm{Y}, m_{Y}\right)$ has a totally $m_{w g}$-closed graph $\mathrm{G}(\mathrm{f})$. If $\mathrm{f}$ is surjective totally $m_{w g^{-}}$open function, then $\mathrm{Y}$ is $m_{w g}$-ultra hausdroff.

Proof: Let $y_{1}$ and $y_{2}$ be any distinct points of $Y$. Since $f$ is surjective $f(x)=y_{1}$ for some $x$ $\in X$ and $\left(x, y_{2}\right) \in(X \times Y) \backslash G(f)$. By the definition, there exists a mwg-clopen set $U$ of $X$ and $\mathrm{V} \in \mathrm{O}(\mathrm{Y})$ such that $\left(\mathrm{x}, \mathrm{y}_{2}\right) \in \mathrm{U} \times \mathrm{V}$ and $(\mathrm{U} \times \mathrm{V}) \cap \mathrm{G}(\mathrm{f})=\Phi$. Then, we have $\mathrm{f}(\mathrm{U}) \cap \mathrm{V}$ $=\Phi$. Since $\mathrm{f}$ is totally $m_{w g^{-}}$open, then $\mathrm{f}(\mathrm{U})$ is mwg-clopen such that $\mathrm{f}(\mathrm{x})=\mathrm{y}_{1} \in \mathrm{f}(\mathrm{U})$. This implies that $\mathrm{Y}$ is $m_{w g}$-ultra hausdroff.

Definition 4.18. A space $\left(X, m_{X}\right)$ is said to be

i. $\quad m_{w g}$-space if every mwg-open set of $\mathrm{X}$ is $\mathrm{m}$-open in $\mathrm{X}$.

ii. $\quad m_{w g}$ - connected if it cannot be written as the union of two nonempty disjoint mwg-open sets.

Theorem 4.19. If the function $\mathrm{f}:\left(\mathrm{X}, m_{X}\right) \rightarrow\left(\mathrm{Y}, m_{Y}\right)$ is totally $\mathrm{m}$ - continuous and $\mathrm{X}$ is $m_{w g^{-}}$space, then $\mathrm{f}$ is totally $m_{w g}$ - continuous.

Proof of the theorem is obvious. 
On Minimal Topological Totally Closed Graphs

Theorem 4.20. If $\mathrm{f}:\left(\mathrm{X}, m_{X}\right) \rightarrow\left(\mathrm{Y}, m_{Y}\right)$ is a totally $m_{w g^{-}}$continuous function from a $m_{w g}$ - connected space $\mathrm{X}$ onto any space $\mathrm{Y}$, then $\mathrm{Y}$ is an indiscrete space.

Proof: Suppose that $\mathrm{Y}$ is not indiscrete. Let $\mathrm{A}$ be a proper non-empty m-open subset of $\mathrm{Y}$. Then $\mathrm{f}^{-1}(\mathrm{~A})$ is a proper non-empty mwg-clopen subset of $\left(\mathrm{X}, m_{X}\right)$, which is a contradiction to the fact that $\mathrm{X}$ is $m_{w g}$ - connected.

Theorem 4.21. Let $\mathrm{X}$ be $m_{w g^{-}}$connected, if $\mathrm{f}:\left(\mathrm{X}, m_{X}\right) \rightarrow\left(\mathrm{Y}, m_{Y}\right)$ is a totally $m_{w g^{-}}$ continuous function with totally $m_{w g}$-closed graph, then $\mathrm{f}$ is constant.

Proof: Suppose that $\mathrm{f}$ is not constant. Then there exist two points $\mathrm{x}$ and $\mathrm{y}$ of $\mathrm{X}$ such that $\mathrm{f}(\mathrm{x}) \neq \mathrm{f}(\mathrm{y})$. Then we have $(\mathrm{x}, \mathrm{f}(\mathrm{y})) \notin \mathrm{G}(\mathrm{f})$. Since $\mathrm{G}(\mathrm{f})$ is totally $m_{w g}$-closed graph, there exist a mwg-clopen set $U$ of $X$ and $V \in O(Y)$ such that $f(U) \cap V=\Phi$. Hence $U \cap f^{-1}(V)$ $=\Phi$. This is contradiction with the $m_{w g}$ - connectedness of X.

Theorem 4.22. If $\mathrm{f}:\left(\mathrm{X}, m_{X}\right) \rightarrow\left(\mathrm{Y}, m_{Y}\right)$ is a totally $m_{w g}$ - continuous surjective function and $\mathrm{X}$ is $\mathrm{m}$-connected, then $\mathrm{Y}$ is $m_{w g^{-}}$connected space.

Proof: Suppose $\mathrm{Y}$ is not $m_{w g^{-}}$connected space. Let $\mathrm{U}$ and $\mathrm{V}$ from disconnection of $\mathrm{Y}$. Then $U$ and $V$ are mwg-open sets in $Y$ and $Y=U \cup V$ where $U \cap V=\Phi$. Also $X=f^{-1}(Y)$ $=\mathrm{f}^{-1}(\mathrm{U} \cup \mathrm{V})=\mathrm{f}^{-1}(\mathrm{U}) \cup \mathrm{f}^{-1}(\mathrm{~V})$, where $\mathrm{f}^{-1}(\mathrm{U})$ and $\mathrm{f}^{-1}(\mathrm{~V})$ are non empty mwg-clopen sets in $\mathrm{X}$, because $\mathrm{f}$ is totally $m_{w g^{-}}$continuous. Further $\mathrm{f}^{-1}(\mathrm{U}) \cap \mathrm{f}^{-1}(\mathrm{~V})=\mathrm{f}^{-1}(\mathrm{U} \cap \mathrm{V})==\Phi$. This implies $\mathrm{X}$ is not connected, which is a contradiction. Hence $\mathrm{Y}$ is $m_{w g^{-}}$connected space.

Definition 4.23. A space $\left(X, m_{X}\right)$ is said to be

i. Totally $m_{w g}$-Compact if every mwg-clopen cover of $\mathrm{X}$ has a finite subcover.

ii. Countably $m_{w g^{-}}$Compact if every mwg-clopen countably cover of $\mathrm{X}$ has a finite subcover.

iii. Totally $m_{w g^{-}}$Lindelof if every mwg-clopen cover of $\mathrm{X}$ has a countable subcover.

Definition 4.24. A subset $A$ of a space $X$ is said to be totally $m_{w g}$-Compact relative to $X$ if every cover of A mwg-clopen sets of $\mathrm{X}$ has a finite subcover.

Theorem: 4.25. If a function $\mathrm{f}\left(\mathrm{X}, m_{X}\right) \rightarrow\left(\mathrm{Y}, m_{Y}\right)$ is totally $m_{w g^{-}}$continuous and $\mathrm{A}$ is totally $m_{w g}$-Compact relative to $\mathrm{X}$, then $\mathrm{f}(\mathrm{A})$ is $\mathrm{m}$-compact in $\mathrm{Y}$.

Proof: Let $\left\{B_{\alpha}: \alpha \in I\right\}$ be any cover of $f(A)$ by m-open sets of the subspace $\mathrm{f}(\mathrm{A})$. For each $\alpha \in I$, there exists a m-open set $A_{\alpha}$ of $Y$ such that $B_{\alpha}=K_{\alpha} \cap \mathrm{f}(\mathrm{A})$. For each $\mathrm{x} \in \mathrm{A}$, there exists $\alpha_{\mathrm{x}} \in \mathrm{I}$ such that $\mathrm{f}(\mathrm{x}) \in \mathrm{A}_{\alpha_{\mathrm{x}}}$ and there exists $\mathrm{U}_{\mathrm{x}} \in m_{X}-\mathrm{WGCO}(\mathrm{X})$ containing $\mathrm{x}$ such that $f\left(U_{x}\right) \subset A_{\alpha x}$. Since the family $\left\{U_{x}: x \in K\right\}$ is cover of A by mwg-clopen sets of $K$, there exists a finite subset $A_{0}$ of $A$ such that $A \subset\left\{U_{x}: x \in A_{0}\right\}$. Therefore, we obtain $\mathrm{f}(\mathrm{A}) \subset \mathrm{U}\left\{\mathrm{f}\left(\mathrm{U}_{\mathrm{x}}\right): \mathrm{x} \in \mathrm{A}_{0}\right\}$ which is subset of $\mathrm{U}\left\{\mathrm{A}_{\alpha_{\mathrm{x}}}: \mathrm{x} \in \mathrm{A}_{0}\right\}$. Thus, $\mathrm{f}(\mathrm{A})=\cup\left\{\mathrm{A}_{\alpha_{\mathrm{x}}}: \mathrm{x} \in\right.$ $\left.\mathrm{A}_{0}\right\}$ and $\mathrm{f}(\mathrm{A})$ is $\mathrm{m}$-compact.

Theorem 4.26. Let $\mathrm{f}:\left(\mathrm{X}, m_{X}\right) \rightarrow\left(\mathrm{Y}, m_{Y}\right)$ be a totally $m_{w g}$ - continuous surjective function, then the following statements hold: 


\section{Sheeba and N. Nagaveni}

i. If $\mathrm{X}$ is totally $m_{w g}$ - Lindelof, then $\mathrm{Y}$ is $\mathrm{m}$ - Lindelof

ii. If $\mathrm{X}$ is countably $m_{w g^{-}}$Compact, then $\mathrm{Y}$ is m-countably compact.

Proof: Let $\left\{\mathrm{B}_{\alpha}: \alpha \in \mathrm{I}\right\}$ be an m-open cover of Y. Since $\mathrm{f}$ is totally $m_{w g^{-}}$continuous, then $\left\{\mathrm{f}^{-1}\left(\mathrm{~V}_{\alpha}\right): \alpha \in \mathrm{I}\right\}$ is a mwg-clopen cover of $\mathrm{X}$. Since $\mathrm{X}$ is totally $m_{w g^{-}}$Lindelof, there exists a countable subset $\mathrm{I}_{0}$ of $\mathrm{I}$ such that $\mathrm{X}=\mathrm{U}\left\{\mathrm{f}^{-1}\left(\mathrm{~V}_{\alpha_{\mathrm{X}}}\right): \alpha \in \mathrm{I}_{0}\right\}$ and $\mathrm{Y}$ is mLindelof. (ii) similar to (i).

Definition 4.27. A $m_{w g^{-}}$frontier of a subset $\mathrm{A}$ of $\mathrm{X}$ is $m_{w g^{-}} \mathrm{fr}(\mathrm{A})=m_{w g^{-}} \mathrm{Cl}(\mathrm{A})$ $\cap m_{w g^{-}} \mathrm{Cl}(\mathrm{X} \backslash \mathrm{A})$.

Theorem 4.28. The set of all points $\mathrm{x} \in \mathrm{X}$ in which a function $\mathrm{f}:\left(\mathrm{X}, m_{X}\right) \rightarrow\left(\mathrm{Y}, m_{Y}\right)$ is not totally $m_{w g}$ - continuous is the union of $m_{w g}$ - frontier of the inverse image of m-open sets containing $\mathrm{f}(\mathrm{x})$.

Proof: Suppose that $\mathrm{f}$ is not totally $m_{w g^{-}}$continuous at $\mathrm{x} \in \mathrm{X}$. Then there exists a $\mathrm{m}$ open set $\mathrm{V}$ of $\mathrm{Y}$ containing $\mathrm{f}(\mathrm{x})$ such that $\mathrm{f}(\mathrm{U})$ is not contained in $\mathrm{V}$ for each $\mathrm{U} \in m_{X^{-}}$ $\mathrm{WGO}(\mathrm{X})$ containing $\mathrm{x}$ and hence $\mathrm{x} \in m_{w g^{-}} \mathrm{Cl}\left(\mathrm{X} \backslash \mathrm{f}^{-1}(\mathrm{~V})\right)$. On the other hand, $\mathrm{x} \in \mathrm{f}^{-1}(\mathrm{~V})$ $\subset m_{w g^{-}} \mathrm{Cl}\left(\mathrm{f}^{-1}(\mathrm{~V})\right)$ and hence $\mathrm{x} \in m_{w g^{-}} \mathrm{fr}\left(\mathrm{f}^{-1}(\mathrm{~V})\right)$.

Conversely, suppose that $\mathrm{f}$ is totally $m_{w g^{-}}$continuous at $\mathrm{x} \in \mathrm{X}$ and let $\mathrm{V}$ be a m-open set of $Y$ containing $f(x)$. Then there exists $U \in \operatorname{MWGO}(X)$ containing $x$ such that $U \subset \mathrm{f}^{-}$ ${ }^{1}(\mathrm{~V})$. Hence, $\mathrm{x} \in m_{w g}$-Int $\left(\mathrm{f}^{-1}(\mathrm{~V})\right)$. Therefore, $\mathrm{x} \in m_{w g}-\mathrm{fr}\left(\mathrm{f}^{-1}(\mathrm{~V})\right)$ for each $\mathrm{m}$-open set $\mathrm{V}$ of $\mathrm{Y}$ containing $\mathrm{f}(\mathrm{x})$.

\section{Conclusion}

In this paper, we introduced the new class of graph functions called as minimal weakly generalized closed graph $\left(m_{w g}\right.$-closed graph) and totally $m_{w g}$-closed graph in minimal structure space. Many of the their properties with some new continuous functions such as quasi mwg-continuous and totally mwg-continuous functions are studied and their characterisations with separation axioms, compact spaces, connected spaces and Lindelof spaces as introduced in m-spaces using minimal weakly generalized closed sets are analyzed.

Acknowledgment. The authors are thankful to the reviewers for their valuable comments and suggestions to improve this research paper.

\section{REFERENCES}

1. M.Caldas, S.Jafari and N.Rajesh, Properties of totally b-Continuous functions, Analele stiintifice ale universitatii "Al.I. Cuza" Din IASI (S. N.) Matematica, Tomul $L V$, , (2009) $119-130$.

2. M.K.Ghosh, Separation axioms and graphs of functions in nano topological spaces via nano $\beta$-open sets, Annals of Pure and Applied Mathematics, 14(2) (2017) 213223.

3. A.A.Hakawati and M.Abu-Eideh, On strong topological aspects in Uryson spaces, Annals of Pure and Applied Mathematics, 16(1) (2018) 117-125.

4. W.K.Min, m-semiopen sets and M-semicontinuous functions on spaces with Minimal structures, Honam Math. J., 31(2) (2009) 239-245. 


\section{On Minimal Topological Totally Closed Graphs}

5. W.K.Min, On minimal semi continuous functions, Commun. Korean Math. Soc. 27(2) (2012) 341-345.

6. M.Mocanu, On m-Compact spaces, Rendiconti del Circolo Matematico di Palermo, Series II, Tomo LIII, (2005) 1-26.

7. T.Noiri and V.Popa, A unified theory of weakly g-closed sets and weakly gcontinuous functions, Srajevo Journal of Mathematics, 9 (21) (2013) 129-142.

8. T.Noiri and V.Popa, A generalization of some forms of g- irresolute functions, European J. Pure \& Appl. Math, 2(4) (2009) 473 - 493.

9. T.Noiri and V.Popa, The unified theory of certain types of generalizations of lindelöf spaces, Emonstratio Mathematica, XLIII(1) (2010) 203 -212.

10. T.M.Nour, Totally semi-continuous Functions, Indian J. Pure appl. Math., 26(7) (1995) 675-678.

11. R.Parimelazhagan, N.Nagaveni and Sai sundara Krishnan, On mg-continuous functions in Minimal Structure, Proc. Int. Conf. Engineers and computer scientists, I (2009) 18 - 20.

12. V.Popa and T.Noiri, On M-continuous Functions, Anal. Univ. Dunarea de Jos"Galati, Ser. Mat. Fiz. Mec. Teor., 18 (23) (200) 31-41.

13. V.Popa and T.Noiri, On the definition of some generalized forms of continuity under minimal conditions, Mem. Fac. Sci. Kochi Univ. Ser. A Math., 22 (2001) 9 - 19.

14. V.Popa and T.Noiri, A unified theory of weak continuity for functions, Rendiconti del Circolo Matematico di Palermo, Series II, Tomo LI (2002) 439-464. 